\title{
Estudo de um Ciclo Menstrual em Adolescentes Eumenorréicas
}

\section{Study of the Menstrual Cycle in Eumenorrheic Adolescents}

Autora: Zuleide Aparecida Félix Cabral

Orientador: Prof. Dr. Laudelino de Oliveira Ramos

Tese apresentada à Faculdade de Medicina da Universidade de São Paulo, para a obtenção do Título de Doutor em Ciências, em 12 de dezembro de 2003.

Objetivo: avaliar um ciclo menstrual de adolescentes eumenorréicas.

Casuística e Métodos: foram estudadas 55 adolescentes entre 14 e 19 anos, com 12 ou mais meses após a menarca. Investigaram-se os valores séricos de $\mathrm{FSH}$ no início do ciclo menstrual, a porcentagem de ovulação, o diâmetro folicular médio pré-ruptura ovular (DFM), o datamento do endométrio, valores de progesterona na fase lútea, a intensidade de vascularização e o índice de resistência do corpo lúteo (IR). As correlações avaliadas incluíram: valores de FSH com a duração da fase folicular (DFF), a DFF e o tempo decorrido da menarca, valores de progesterona e a correlação com a DFF, tempo decorrido da menarca, vascularização e o índice de resistência do corpo lúteo. Resultados: observou-se correlação negativa entre os valores de FSH e a DFF e ausência de correlação entre a DFF e o tempo decorrido da menarca. O DFM foi de $18,7 \mathrm{~mm}$. A porcentagem de ovulação diagnosticada pela ultra-sonografia transvaginal foi de $100 \%$. As biópsias de endométrio demonstraram padrão histológico de aspecto secretor, sendo $85,5 \%$ dos endométrios compativeis com o dia da fase lútea. A média das concentrações de progesterona foi de 10,6 ng/ml. As concentrações de progesterona no $12^{\circ}$ dia após a ovulação foram menores no grupo com DFF maior ou igual a 16 dias, em comparação ao grupo com DFF menor do que 16 dias. O IR foi de 0,41 . Não foi evidenciada correlação entre as concentrações de progesterona com a intensidade de vascularização e o IR do corpo lúteo.

Conclusões: as adolescentes estudadas demonstraram elevado potencial reprodutivo. A regularidade menstrual é parâmetro clínico importante, mais do que o período de tempo decorrido após a menarca no diagnóstico da ovulação.

Palavras-chave: Adolescentes. Biópsia do endométrio. Ciclo menstrual. Ultra-sonografia.

\section{8 a 30 de maio de 2004}

Hotel

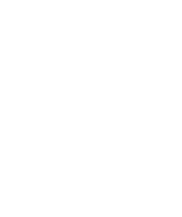
Tel.:
(81)
3222-5112
Fax.:
e-mail:
(81) 3221-2843
sogope1@ terra.com.br

Gravatá

\author{
P E \\ Informações: \\ SOGOPE
}

